Calvino and the Age of Neorealism 


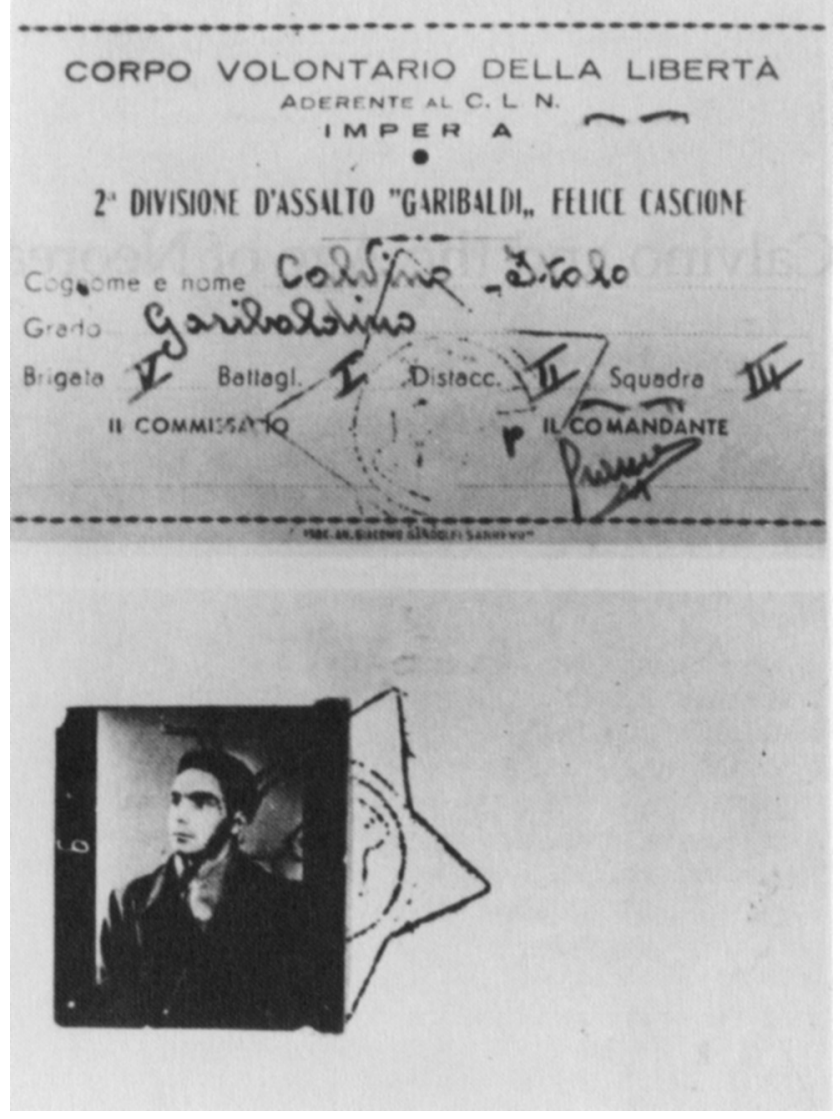




\section{Lucia Re}

\section{$\mathbf{C} \cdot \mathbf{A} \cdot \mathbf{L} \cdot \mathbf{V} \cdot \mathbf{I} \cdot \mathbf{N} \cdot \mathbf{O}$ and the}

Age of Neorealism:

Fables of Estrangement

ST A N F OR D U N I VERS I T Y PRESS

S T A N F O R D, C A L I F O R N I A 


\section{Stanford University Press}

Stanford, California

(C) 1990 by the Board of Trustees of the

Leland Stanford Junior University

Printed in the United States of America

CIP data appear at the end of the book

Frontispiece: Calvino's partisan card 
This book is lovingly dedicated to the memory of my father, Ettore $\operatorname{Re}(1917-89)$ 



\section{Acknowledgments}

This book was originally conceived and drafted during my tenure of a Fellowship from the National Endowment for the Humanities. Research for the book and the preparation of the manuscript were also supported by several UCLA Academic Senate Grants.

I would like to thank Rebecca West and Gregory Lucente for their perceptive and helpful readings of the manuscript. Marga Cottino-Jones, Peter Haidu, and Vincent Pecora contributed valued insights and advice. Amy Morris, Peggy Kidney, and Pasquale Verdicchio provided essential and much appreciated assistance as bibliographers and typists. I am grateful to Caroline McManus for her fine copyediting and to Helen Tartar of Stanford University Press for her extraordinary promptness and patience. My thanks as well to Kathy Komar, Ross Shideler, Arnold Band, Larry Barth, Francesca Santovetti, Pier Maria Pasinetti, and Paul Vangelisti for their interest in my work, their support, and their friendship. Finally, to Jon Snyder, my best and most critical reader over the last few years, I owe unlimited gratitude for his unconditional love and his dedication in following the making of the book every step of the way.

L.R. 
